\title{
Estimation of the proportion of genetically unbalanced spermatozoa in the semen of boars carrying chromosomal rearrangements using FISH on sperm nuclei
}

\author{
Alain Pinton ${ }^{\mathrm{a}}$, Alain Ducos ${ }^{\mathrm{a} *}$, Martine YerLE $^{\mathrm{b}}$ \\ ${ }^{a}$ UMR INRA-ENVT Cytogénétique des populations animales, École nationale vétérinaire de \\ Toulouse, 23, chemin des Capelles, 31076 Toulouse Cedex 3, France \\ ${ }^{\mathrm{b}}$ Laboratoire de génétique cellulaire, Institut national de la recherche agronomique, \\ Auzeville BP 27, 31326 Castanet-Tolosan Cedex, France
}

(Received 12 March 2003; accepted 23 May 2003)

\begin{abstract}
Many chromosomal rearrangements are detected each year in France on young boars candidates for reproduction. The possible use of these animals requires a good knowledge of the potential effect of the rearrangements on the prolificacy of their mates. This effect can be estimated by an accurate determination of the rate of unbalanced spermatozoa in the semen of boars which carry the rearrangements. Indeed, these spermatozoa exhibiting normal fertilizing ability are responsible for an early embryonic mortality, and then, for a decrease of the litter sizes. The "spermFISH" technique, i.e. fluorescent in situ hybridization on decondensed sperm heads, has been used on several occasions in Man, in this perspective. In livestock species, this method was formerly used mainly for semen sexing purposes. We used it, for the first time, to estimate the rates of imbalance in the semen of four boars carrying chromosomal rearrangements: two reciprocal translocations, $\operatorname{rcp}(3 ; 15)(\mathrm{q} 27 ; \mathrm{q} 13)$ and $\mathrm{rcp}(12 ; 14)(\mathrm{q} 13 ; \mathrm{q} 21)$, as well as two independent cases of trisomy 18 mosaicism. The rates of unbalanced gametes were relatively high for the two reciprocal translocations ( $47.83 \%$ and $24.33 \%$, respectively). These values differed from the apparent effects of the rearrangements estimated using a limited number of litters: a decrease in prolificacy of 23\% (estimation obtained using the results of 6 litters) and 39\% (57 litters), respectively for the $3 / 15$ and 12/14 translocations. The imbalance rates were much lower for the trisomy mosaics $(0.58 \%$ and $1.13 \%)$, suggesting a very moderate effect of this special kind of chromosomal rearrangement.
\end{abstract}

reciprocal translocation / trisomy mosaic / gamete / fluorescent in situ hybridization / chromosome

\footnotetext{
*Corresponding author: a.ducos@envt.fr
} 


\section{INTRODUCTION}

Constitutional chromosomal rearrangements are relatively common genetic abnormalities in most animal species. In man, they are responsible for reproductive disorders and important congenital abnormalities. The estimated frequency in live born infants is about $0.7 \%$ [3]. Recently, a similar frequency $(0.4 \%)$ was estimated in pigs, in a sample of 3500 young purebred boars controlled before reproduction in artificial insemination centres [12]. In livestock species, constitutional chromosomal abnormalities affect the reproductive performance of animals which carry the rearrangements, or the reproductive performance of their mates. The reason is the production of genetically unbalanced gametes responsible for an early embryonic mortality. The numerous chromosomal analyses carried out in hypoprolific boars has allowed for the identification of many chromosomal rearrangements [27]. The economical consequences of such abnormalities can be very important if the animals which carry the rearrangements have a high number of mates, as is generally the case for reproducers used in artificial insemination centres [30]. These economical considerations result in the establishment of systematic control programs of young purebred animal candidates for reproduction in several selected porcine populations $[9,11]$. The analyses carried out have allowed the discovery of various chromosomal rearrangements carried by young animals controlled before reproduction, including reciprocal translocations, peri- and paracentric inversions, as well as trisomy mosaics. In some cases, familial analyses have allowed us to find the rearrangement on numerous relatives. The frequency of some abnormalities has turned out to be important in certain populations: up to $10 \%$ of the animals carried the anomaly. Since these chromosomal rearrangements have potentially harmful effects for breeders, their eradication has, up to now, been systematically advised. However, on several occasions, this recommendation is difficult to apply. Indeed, in some small-sized populations, the eradication implies the elimination of numerous animals having high additive genetic values, thus decreasing the efficiency of the selection schemes. In such situations, eradication is relevant only if the rearrangements are effectively responsible for an important alteration of the reproductive performance. Therefore, a precise knowledge of the potential effect of the rearrangements is needed to adjust the selection decisions. Test matings can be carried out to estimate this effect, but this strategy is long and costly. Since the unbalanced gametes responsible for embryonic loss (and the subsequent litter size reduction) have normal fertilizing abilities [10,29], an alternative strategy is the direct in vitro estimation of the proportion of unbalanced gametes in the semen of animals carrying the rearrangements. Different technical approaches initially developed in Man can be used in this perspective. One is based on 
the in vitro penetration of hamster oocytes by the spermatozoa of the animal of interest, followed by the fixation and analysis of pronuclei chromosomes [35]. This approach is burdensome and allows only the analysis of a limited number of gametes. Moreover, it is potentially biased since only the spermatozoa that effectively fecundate the hamster oocytes are studied. Since 1997, two molecular cytogenetics procedures applied on decondensed sperm heads have been generally preferred: fluorescent in situ hybridization of DNA probes (spermFISH), and primed in situ DNA labeling (PRINS). Theoretically, the socalled "spermFISH" technique allows the distinction between normal/balanced and unbalanced spermatozoa in the semen of individuals carrying chromosomal rearrangements. In reciprocal translocations for instance, the first ones are mainly produced by alternate segregation mechanisms, whereas the others mainly result from adjacent-1 or -2 and 3:1 segregations [3,8]. The simultaneous hybridization of three probes on decondensed sperm heads allows the distinction between the different segregation products. Two probes must be chosen in the centromeric regions of both chromosomes involved in the translocation, whereas the third one must be located on one translocated fragment. Each probe is revealed using a specific fluorochrome combination, e.g. red, green, and red+green = yellow. Whatever the segregation mechanisms involved, only one fluorescent phenotype corresponds to balanced spermatozoa (YRG or Yellow/Red/Green phenotype, i.e. one signal for each probe). YRG spermatozoa are normal ones or balanced spermatozoa carrying translocated chromosomes (Fig. 1; see also [19] for more details).

This approach has been used successfully on many occasions in Man to study the segregation products of various chromosomal rearrangements $[1,4$, $5,7,20,21,40]$. In livestock species, the spermFISH technique was formerly used to quantify X- and Y-bearing sperm in cattle [17,28,31,36] and pigs [23], as well as for the estimation of aneuploidy rates in pigs [34]. We used it for the first time to estimate the proportion of unbalanced gametes in the semen of boars carrying different chromosomal rearrangements, and to predict their effects on reproduction.

\section{MATERIALS AND METHODS}

\subsection{Animals and chromosomal rearrangements studied}

Three chromosomal rearrangements were considered.

Two of them were reciprocal translocations. The first one, $\operatorname{rcp}(3 ; 15)$ (q27;q13), was identified in a 10 month-old purebred Large White boar controlled before reproduction in an artificial insemination (AI) centre. Six litters were sired by this boar before culling, for experimental purposes. The average size of these litters (9.2 piglets born) was $23 \%$ lower than those obtained from 
Table I. Description of the probes used in the "spermFISH" applications.

\begin{tabular}{ccccccc}
\hline Rearrangement & Chromosomes & BACs & Marker/Gene & Location & Labeling (*) & Color \\
\hline $\mathrm{t}(3 / 15)$ & 3 & $526 \mathrm{E} 5$ & STAG3 & $3 \mathrm{p} 16$ & $\mathrm{~B}+\mathrm{D}$ & Yellow \\
& $15(1)$ & $534 \mathrm{~A} 6$ & SW2072 & $15 \mathrm{q} 12$ & $\mathrm{D}$ & Green \\
& $15(2)$ & $479 \mathrm{H} 1$ & S1001 & $15 \mathrm{q} 25$ & $\mathrm{~B}$ & Red \\
\hline $\mathrm{t}(12 / 14)$ & 12 & $1008 \mathrm{~B} 4$ & SW943 & $12 \mathrm{p} 13$ & $\mathrm{D}$ & Green \\
& $14(1)$ & $498 \mathrm{D} 8$ & PER V & $14 \mathrm{q} 11$ & $\mathrm{~B}+\mathrm{D}$ & Yellow \\
& $14(2)$ & $1059 \mathrm{H} 9$ & FGFA2 & $14 \mathrm{q} 28$ & $\mathrm{~B}$ & Red \\
\hline trisomy 18 & Control : 3 & 526E5 & STAG3 & $3 \mathrm{p} 16$ & $\mathrm{~B}$ & Red \\
& 18 & 344H5 & WAP & $18 \mathrm{q} 24$ & $\mathrm{D}$ & Green \\
\hline
\end{tabular}

(*) B: biotin; D: digoxigenin; B+D: biotin+digoxygenin.

the contemporary boars of the herd (12 piglets born, on average). The second one, rcp(12;14)(q13;q21), was identified in a 15 month-old boar selected from a composite line based on Duroc and Large White breeds, and used in a multiplication herd. The litters sired by this boar $(n=57)$ had a reduced size (6.7 piglets born) as compared with those obtained from the contemporary boars of the herd (10.98, i.e. a decrease in prolificacy of 39\%).

The third anomaly was a trisomy 18 mosaic. It was found independently in two 9 month-old boar candidates for reproduction in AI centres. One was of the French Landrace breed, the other one of the Piétrain breed. In both cases, trisomic cells were found in various tissues (skin, blood, lung). The average proportion of trisomic cells was $23 \%$ and $50 \%$, respectively for the two boars. These two animals were culled by the breeders before reproduction.

\subsection{Preparation of the probes}

Probes were prepared using BAC clones isolated from the Inra swine BAC library [33]. These clones contained genes or microsatellite markers previously located on the porcine cytogenetic (http://www.toulouse.inra.fr/lgc/pig/ cyto/cyto.htm) and RH maps [18] (Tab. I). Biotin or/and digoxigenin labeling of the probes was carried out using random priming.

The specificity of all probes was previously tested on metaphases obtained from lymphocyte cultures.

For each reciprocal translocation, three probes were hybridized simultaneously on decondensed sperm heads: probe 1 labeled with biotin, probe 2 labeled with digoxigenin, and probe 3 labeled with both biotin and digoxygenin (Tab. I, Fig. 2).

For the two trisomy 18 mosaic cases plus one control (boar with a normal karyotype), two probes were hybridized simultaneously on decondensed sperm head preparations. One probe was specific for chromosome 18, the other one for chromosome 3 (the same as the one used for the $3 / 15$ translocation) (Tab. I). 
Chromosomal imbalance in the semen of boars

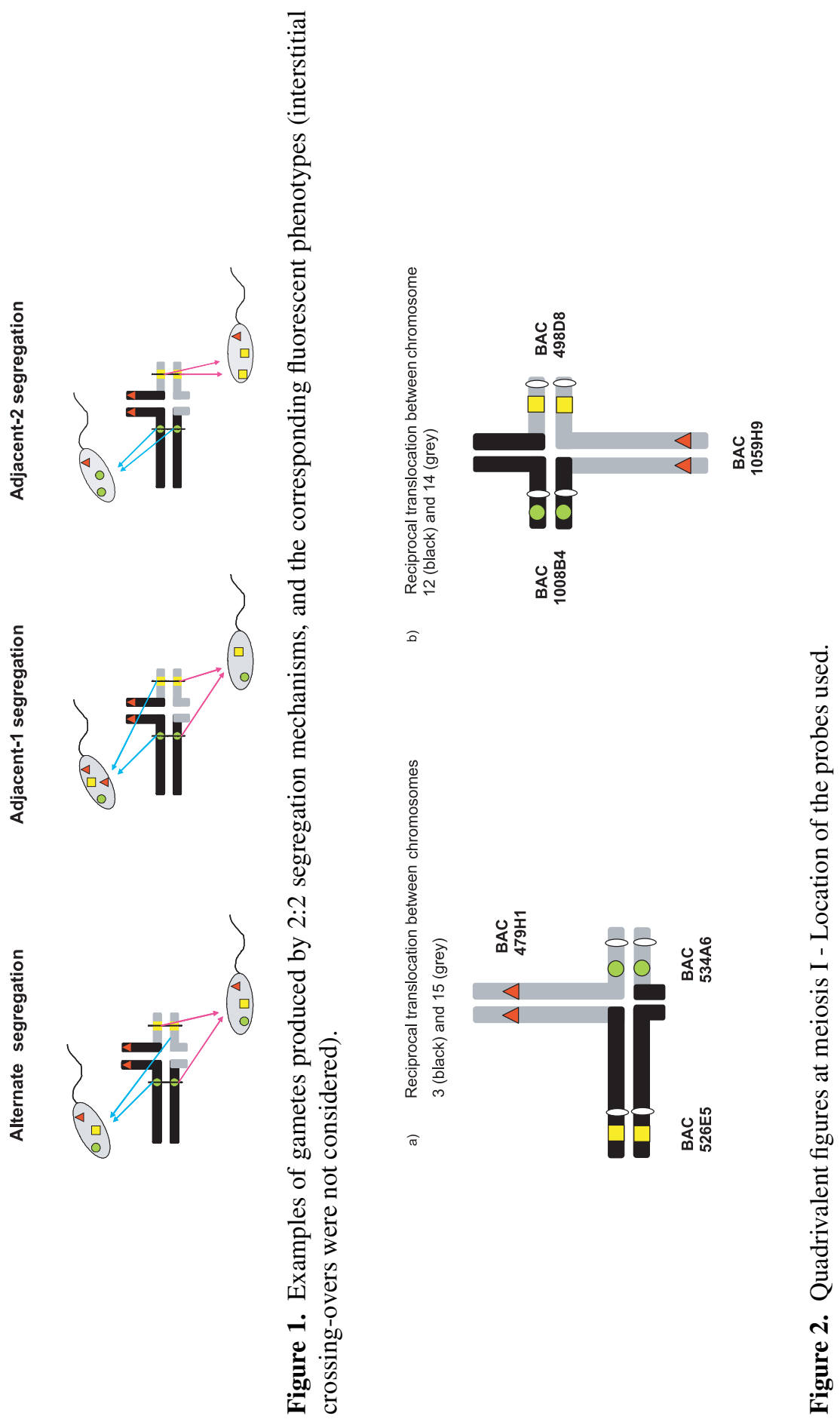




\subsection{Sperm preparation, hybridization and signal analysis}

Sperm preparations were carried out using commercial AI doses. The samples were first centrifuged (1200 rpm, $6 \mathrm{~min})$, then frozen $\left(-20^{\circ} \mathrm{C}\right)$ in a $90 \%$ calf serum $/ 10 \%$ glycerol solution. Before spreading, the samples were defrosted and washed in a PBS solution at room temperature. The slides were stored overnight at room temperature. The sperm preparations were then fixed in ethanol:acetic acid (3:1) for $20 \mathrm{~min}$. Decondensation was carried out according to the protocol developed by Hassanane et al. [17], i.e. treatment with a dithiothreitol (DTT)/papain solution (1.25 g papain, Merck, plus $0.155 \mathrm{~g}$ DTT, Sigma, dissolved in $100 \mathrm{~mL} 0.2 \mathrm{M}$ Tris-buffer, $\mathrm{pH}$ 8.6) at room temperature. The optimal decondensation time ( 8 to $9 \mathrm{~min}$ ) was determined experimentally.

Hybridizations were carried out as described by Yerle et al. [41]. Biotinlabeled probes were revealed using streptavidin coupled to the Alexa 594 fluorochrome (Molecular Probe). Signal amplification was achieved using rabbit antistreptavidin antibody (Bethyl) + donkey antirabbit antibody coupled to Alexa 594 (Molecular Probes). Digoxigenin labeled probes were revealed using sheep antidigoxigenin antibody + donkey antisheep antibody coupled to the Alexa 488 fluorochrome (Molecular Probes). The slides were analyzed under a Zeiss Axioskop microscope fitted with a triple bandpass filter. Only sperm heads exhibiting equal intensity signals, separated by a distance of at least the size of one signal, were considered. Three thousand spermatozoa were analyzed for both translocations, 10000 for the trisomy 18 mosaics.

\subsection{Statistical analyses}

A classical $2 \times 2 \chi^{2}$ test with the Yates correction for continuity [6] was used to compare the following proportions: (1) trisomic boar 1 versus the control boar, as well as trisomic boar 2 versus control, for each sperm category (Tab. III); and (2) disomic 18 versus disomic 3 sperm proportions in the semen of trisomic boar 1 and trisomic boar 2 .

\section{RESULTS}

The hybridization rates were higher than $99 \%$ in all cases. Examples of fluorescent phenotypes observed in the case of the $3 / 15$ translocation are shown in Figure 3. The results obtained for the three chromosomal rearrangements are presented in Tables II and III, and are summarized below.

In the case of the $3 / 15$ translocation (Tab. II), the proportion of alternate and adjacent- 1 products was $83.57 \%$. Only $2.93 \%$ of the spermatozoa originated from adjacent-2 segregation. A higher proportion (13.5\%) corresponded 

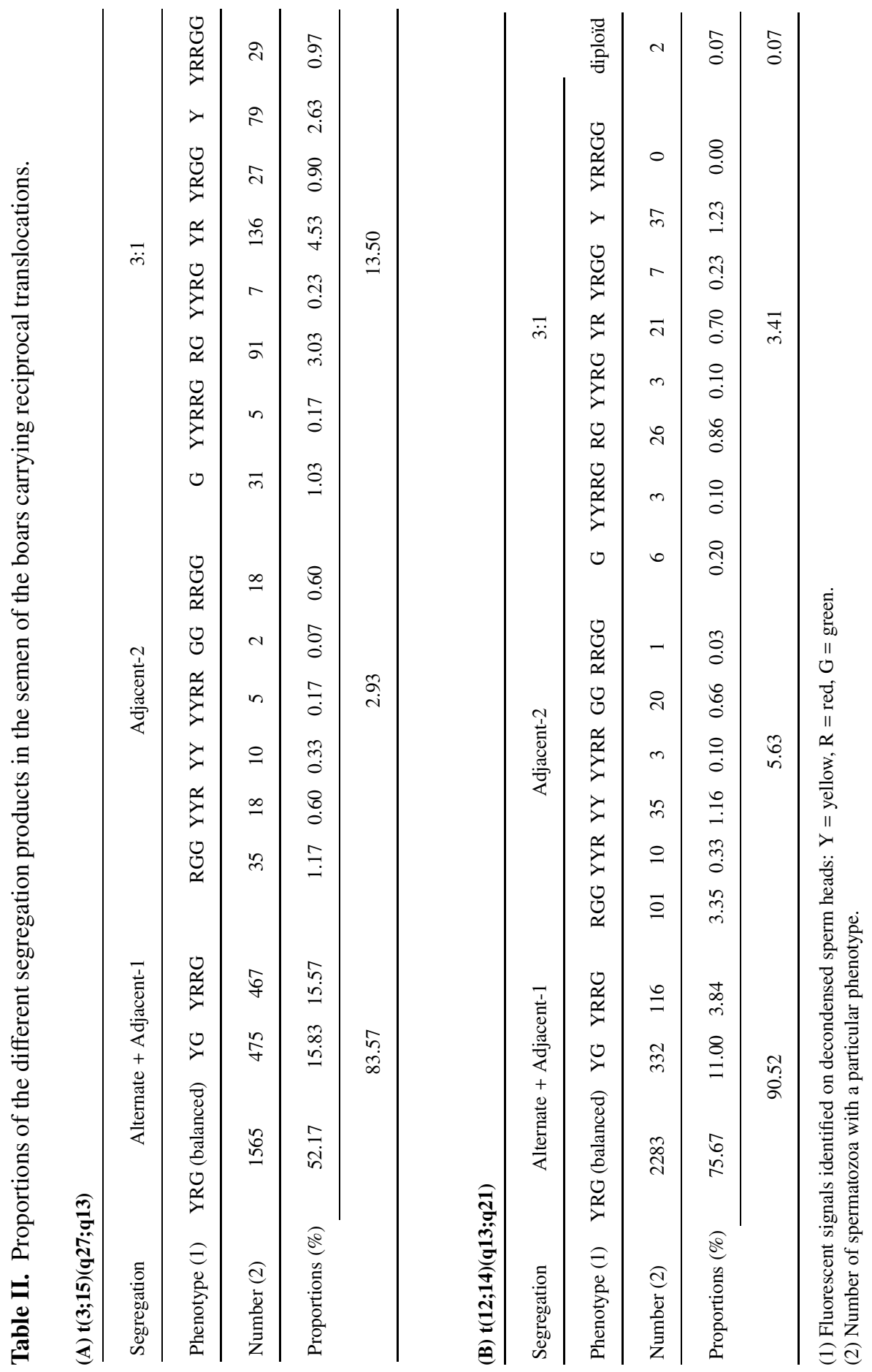


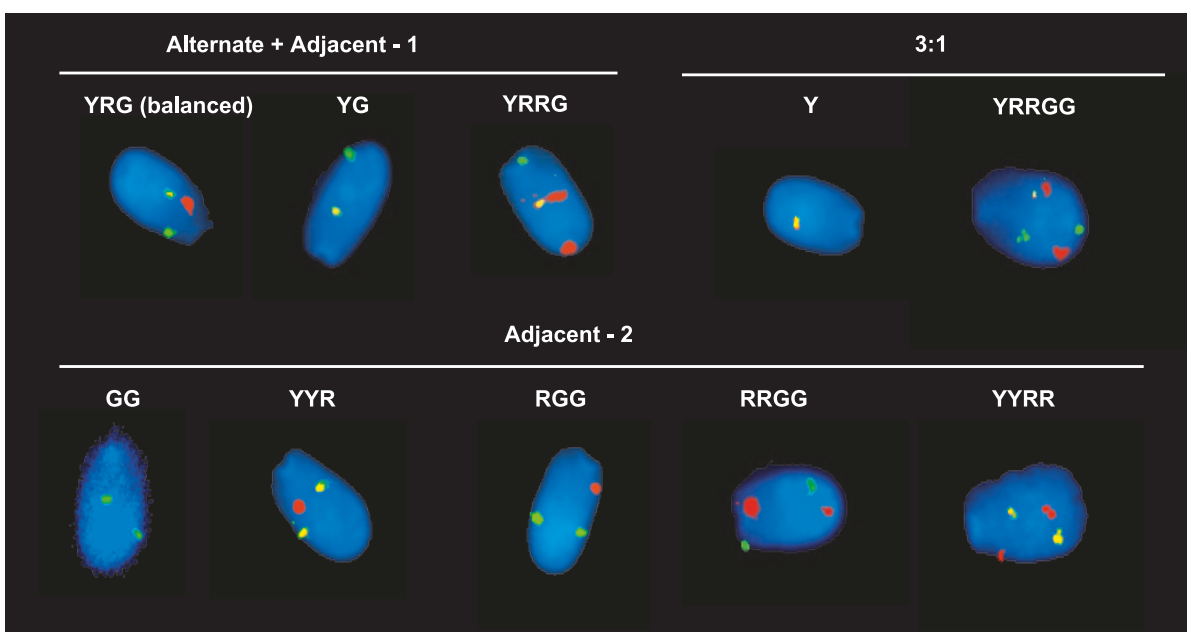

Figure 3. Representative sperm nuclei for the $\mathrm{t}(3 ; 15)(\mathrm{q} 27 ; \mathrm{q} 13)$ translocation carrier, Y: yellow, R: red, G: green.

Table III. Number (and proportion, \%) of the different segregation products in the semen of the boars carrying a trisomy 18 mosaic, and in the semen of a control boar (normal karyotype).

\begin{tabular}{lccccccc}
\hline $\begin{array}{l}\text { Chromosomal } \\
\text { content of the } \\
\text { gametes }\end{array}$ & $\begin{array}{c}\text { Nullisomy } \\
\text { Control boar }\end{array}$ & $\begin{array}{c}\text { Nullisomy } \\
18\end{array}$ & $\begin{array}{c}\text { Disomy } \\
3\end{array}$ & $\begin{array}{c}\text { Disomy } \\
18\end{array}$ & Diploïd & $\begin{array}{c}\text { Normal } \\
\text { (balanced) }\end{array}$ & Total \\
& $(0.08)$ & $(0.03)$ & $(0.03)$ & $(0.02)$ & $(0.02)$ & $(99.82)$ & \\
\hline Trisomy 18 & 17 & 2 & 11 & $24^{* * *}$ & 4 & 10000 & 10058 \\
(boar 1) & $(0.17)$ & $(0.02)$ & $(0.11)$ & $(0.24)$ & $(0.04)$ & $(99.42)$ & \\
\hline Trisomy 18 & $25^{* *}$ & 6 & 10 & $72^{* * *}$ & 2 & 10088 & 10203 \\
(boar 2) & $(0.25)$ & $(0.06)$ & $(0.10)$ & $(0.71)$ & $(0.02)$ & $(98.87)$ & \\
\hline
\end{tabular}

The proportion estimated for the boar carrying the trisomy 18 mosaic (boar 1 or boar 2) was significantly different from the proportion estimated for the control boar:

${ }^{* *}: P<0.01 ;{ }^{* * *}: P<0.001$.

to the 3:1 segregation products. This experiment allowed us to estimate the proportions of balanced and unbalanced spermatozoa $(52.17 \%$ and $47.83 \%$, respectively).

The segregation profile was noticeably different in the case of the 12/14 translocation: $90.52 \%$ of the spermatozoa corresponded to alternate/adjacent1 products, whereas $5.63 \%$ and $3.41 \%$ came from adjacent- 2 and 3:1 segregations, respectively. On the contrary to the $3 / 15$ translocation, 2 diploid spermatozoa were observed. The proportions of balanced and unbalanced sperm were $75.67 \%$ and $24.33 \%$, respectively. 
More than 10000 sperm heads were analyzed for both trisomic and control boars (Tab. III). The simultaneous hybridization of the two probes allowed a distinction between disomic and diploid spermatozoa. The sperm heads exhibiting one unique signal for each probe were considered as normal (balanced). In the semen of the first trisomic boar, a very large majority of spermatozoa were normal (99.42\%). The estimated proportion of disomic 18 sperm, exhibiting two hybridization signals for the chromosome 18 probe, and one signal for chromosome 3 , was $0.24 \%$. This value was higher than the $0.11 \%$ value estimated for disomic 3 spermatozoa in the same sample $(P<0.05)$. The proportion of balanced spermatozoa in the semen of the second trisomic boar was slightly lower (98.87\%). The proportion of disomic 18 sperm was significantly higher for this second trisomic boar than for the first one $(P<0.001)$, but remained very low. As for the first trisomic boar, the proportion of disomic 18 sperm was higher than the proportion of disomic 3 sperm $(P<0.001)$. The proportions of disomic 18 sperm were significantly higher in the semen samples of both trisomic boars than in the control $(P<0.001)$.

\section{DISCUSSION}

The use of the spermFISH technique for the analysis of segregation products in the semen of individuals carrying chromosomal rearrangements has frequently been reported in Man (see for instance [16] for a review). Conversely, such an application has never been carried out before in livestock species.

On the one hand, this method allows an accurate estimation of the proportion of balanced and unbalanced gametes, due to the very large size of the samples studied. On the other hand, for reciprocal translocations, the normal and balanced/translocated gametes, both presenting a YRG phenotype, can not be distinguished. Yet, these two kinds of gametes are the reciprocal products of the same segregation mechanisms (Fig. 1), and therefore should be represented with identical proportions. This method also does not allow an exhaustive description of the segregation profiles. Indeed, the first three phenotypes presented in Table II can be produced by different segregation mechanisms. The YRG phenotype is mainly the result of an alternate segregation. However, if an interstitial crossing-over occurs, the same phenotype can come from adjacent1 segregation. Conversely, the YG and YRRG phenotypes, mainly produced by the adjacent-1 segregation, can also come from an alternate segregation in the case of interstitial crossing-over (see for instance $[19,24]$ for details). Therefore, the alternate and adjacent- 1 segregation products were considered together. 
The two limits discussed above had however, no consequence on the estimation of the proportion of unbalanced gametes, which remained the main objective of our study.

The results obtained for the two porcine reciprocal translocations confirmed the general observations made in Man. The first one was that of the preponderance of alternate and adjacent- 1 segregations. These two kinds of segregations explained between $58 \%$ and $100 \%$ of the gametes in over 34 human reciprocal translocations reviewed by Faraut et al. [13]. The $83.57 \%$ and $90.52 \%$ values estimated here were comparable to those reported for numerous human reciprocal translocations. The variability of the estimated proportions of unbalanced gametes between the two translocations ( $47.83 \%$ and $24.33 \%$, respectively) was also in agreement with well established human results (proportion of imbalance varying between $18 \%$ and $77 \%$ in the review of Pellestor et al. [25], for instance). Such variability was also observed for the proportions of the different segregation products: $31.4 \%$ (3/15 translocation) versus $14.84 \%$ (12/14 translocation) for the adjacent-1 segregation; $2.93 \%$ (3/15 translocation) versus $5.63 \%$ (12/14 translocation) for the adjacent-2 segregation; $13.5 \%(3 / 15$ translocation) versus $3.41 \%$ (12/14 translocation) for the $3: 1$ segregation. The structure of the quadrivalents could explain the latter difference. Indeed, asymetric quadrivalents including a short derived chromosome, such as the one expected in the case of the 3/15 translocation (Fig. 2), are likely to result in an increased proportion of 3:1 segregation products, due to the low number of chiasmatas that can occur between this short chromosome and its counterparts. In the case of the $3 / 15$ translocation, the very short der(15) chromosome is likely to separate prematurely, leading to a 3:1 configuration. Other hypotheses that could explain the variability described above have been discussed thoroughly elsewhere [13-15, 22, 37, 38].

The proportions of unbalanced spermatozoa estimated for the two reciprocal translocations were rather high, and justified the eradication programs carried out by the breeders. In the case of the $3 / 15$ translocation, the estimated rate of imbalance $(47.83 \%)$ is noticeably higher than the apparent effect of the rearrangement ( -2.8 piglets/litter, i.e. a $23 \%$ decrease in prolificacy). Even if the latter value should be considered carefully, due to the limited number of litters available (6), such a difference appeared logical. Indeed, the number of embryos was reduced in the litters sired by the boar carrying the translocation. Therefore, the uterine competition should be reduced, and the piglets more robust at birth. The mortality rate during the gestation and the peripartum periods should be reduced, which would partially compensate for the effect of the chromosomal rearrangement. An inverse result was obtained for the 12/14 translocation: the apparent effect estimated over 57 litters was noticeably higher than the estimated proportion of unbalanced gametes. Several 
explanations can be suggested. On the one hand, a variation of the rate of imbalance during the animal's life could be envisaged. Indeed, in such a situation, one punctual in vitro estimation using spermFISH would not be representative of the real effect of the rearrangement over the whole reproductive career of the boar. On the other hand, direct non chromosomal effects of boars on the prolificacy of their mates have been evidenced on several occasions [2,39]. Many hypoprolific boars with normal karyotypes were found at the time of every genetic evaluation [39]. In the present case, the effects of other non chromosomal factors could cumulate with those of the translocation, and therefore explain an apparent effect higher than the spermFISH prediction. These uncertainties makes it necessary to carry out complementary experiments in order to validate the spermFISH technique as a predictor of the potential effect of chromosomal rearrangements: the analysis of other chromosomal abnormalities, the estimation of the apparent effects of the rearrangements over a higher number of litters, and longitudinal analyses (repeated determination of the segregation profiles over time for several rearrangements). This represents a considerable amount of work.

In the trisomy 18 cases, the contamination of the germinal cell line was suspected. Therefore, the boars carrying the rearrangements were likely to produce a higher proportion of disomic spermatozoa ( 2 chromosomes 18$)$ than normal (control) boars. The results obtained confirmed the contamination of the germinal cell line. However, the very low proportion of unbalanced spermatozoa ( $<2 \%$ in both cases) led to believe that this chromosomal abnormality should have a very limited impact on reproduction. Unfortunately, this hypothesis could not be tested since the boars were culled before reproduction. As shown in Table III, the proportion of nullisomic 3 sperm was significantly higher for the trisomic boar 2 than in the control. The proportions of disomic 3 sperm were also higher in the semen samples of both trisomic boars than in the control, although the differences were not statistically significant. Such results could be explained by the occurrence of interchromosomal effects in the spermatozoa of the trisomy 18 mosaic carriers [26]. Fluorescent in situ hybridization of probes specific for other chromosomes should be carried out to investigate this point.

The sperm analysis carried out in one control boar with a normal karyotype allowed us to estimate the normal aneuploidy rates for chromosomes 3 and 18 . Such results have been reported only once before in the pig species, for chromosomes 1, 10 and X [34]. The results obtained in the present study (nullisomy and disomy rates comprised between $0.02 \%$ and $0.08 \%$ ) are close to those reported by Rubes et al. [34] for the autosomes $(0.075 \%$ and $0.067 \%$ for chromosomes 1 and 10, respectively). However, these values appeared rather 
different than those recently obtained in humans (identical disomy rates for all autosomes: $0.24 \%$ [32]).

In conclusion, the spermFISH technique presented in this paper allows the estimation of the proportion of unbalanced gametes in the semen of reproducers carrying chromosomal rearrangements. Theoretically, this proportion could be used as a predictor of the potential effect of the rearrangements. Complementary experiments remain necessary to definitively validate this approach.

\section{ACKNOWLEDGEMENTS}

We wish to express our gratitude to the staff of the insemination centres, of the selection organizations as well as the herd-stock breeders, for the blood and sperm samples and all the arrangements concerning the animals. We thank also F. Piumi and C. Rogel-Gaillard for providing the BACs, and T. Faraut for his valuable comments on the results. We acknowledge the financial support from the "ministère de l'Agriculture, de la Pêche et des Affaires rurales".

\section{REFERENCES}

[1] Anton E., Blanco J., Egozcue J., Vidal F., Risk assessment and segregation analysis in a pericentric inversion inv(6)(p23q25) carrier using FISH on decondensed sperm nuclei, Cytogenet. Genome Res. 97 (2002) 149-154.

[2] Beauvois E., Labroue F., Bidanel J.P., Étude de facteurs de variation de la taille de portée à la naissance dans les races porcines Large White et Landrace Français, in: Journées Rech. Porcine France, 4-6 February 1997, Vol. 29, Institut technique du porc, Paris, pp. 353-360.

[3] Berger R., Cytogénétique humaine, in: Feingold J., Fellous M., Solignac M. (Eds.), Principes de génétique humaine, Hermann, Paris, 1998, pp. 33-58.

[4] Blanco J., Egozcue J., Clusellas N., Vidal F., FISH on sperm heads allows the analysis of chromosome segregation and interchromosomal effects in carriers of structural rearrangements: results in a translocation carrier, $\mathrm{t}(5 ; 8)(\mathrm{q} 33 ; \mathrm{q} 13)$, Cytogenet. Cell Genet. 83 (1998) 275-280.

[5] Cifuentes P., Navarro J., Blanco J., Vidal F., Miguez L., Egozcue J., Benet J., Cytogenetic analysis of sperm chromosomes and sperm nuclei in a male heterozygous for a reciprocal translocation $\mathrm{t}(5 ; 7)(\mathrm{q} 21 ; \mathrm{q} 32)$ by in situ hybridisation, Eur. J. Hum. Genet. 7 (1999) 231-238.

[6] Dagnélie P., Les tests d'indépendance et les méthodes relatives aux proportions, in: Théorie et méthodes statistiques, applications agronomiques, Vol. 2, Les Presses Agronomiques de Gembloux, Gembloux, 1975, pp. 81-105.

[7] Downie S.E., Flaherty S.P., Matthews C.D., Detection of chromosomes and estimation of aneuploidy in human spermatozoa using fluorescence in situ hybridization, Mol. Hum. Reprod. 3 (1997) 585-598. 
[8] Ducos A., Berland H.M., Pinton A., Seguela A., Darré R., Un reproducteur porcin de qualité doit être indemne d'anomalie chromosomique, Rev. Méd. Vét. 147 (1996) 101-108.

[9] Ducos A., Berland H.M., Pinton A., Séguéla A., Blanc M.F., Darré A., Sans P., Darré R., Les translocations réciproques chez le porc : état des lieux et perspectives, in: Journées Rech. Porcine France, 4-6 February 1997, Vol. 29, Institut technique du porc, Paris, pp. 375-382.

[10] Ducos A., Dumont P., Séguéla A., Pinton A., Berland H.M., Brun-Baronnat C., Darré A., Marquant-Le Guienne B., Humblot P., Boichard D., Darré R., A new reciprocal translocation in a subfertile bull, Genet. Sel. Evol. 32 (2000) 589-598.

[11] Ducos A., Pinton A., Séguéla A., Berland H.M., Brun-Baronnat C., Bonnet N., Darré R., Contrôle chromosomique des populations porcines en France : bilan de 5 années d'activité, in: Journées Rech. Porcine France, 5-7 February 2002, Vol. 34, Institut technique du porc, Paris, pp. 269-275.

[12] Ducos A., Pinton A., Yerle M., Seguela A., Berland H.M., Brun-Baronnat C., Bonnet N., Darré R., Cytogenetic and molecular characterization of eight new reciprocal translocations in the pig species, Estimation of their incidence in French populations, Genet. Sel. Evol. 34 (2002) 389-406.

[13] Faraut T., Mermet M.A., Demongeot J., Cohen O., Cooperation of selection and meiotic mechanisms in the production of imbalances in reciprocal translocations, Cytogenet. Cell Genet. 88 (2000) 15-21.

[14] Goldman A.S., Hulten M.A., Analysis of chiasma frequency and first meiotic segregation in a human male reciprocal translocation heterozygote, $\mathrm{t}(1 ; 11)(\mathrm{p} 36.3 ; \mathrm{q} 13.1)$, using fluorescence in situ hybridisation, Cytogenet. Cell Genet. 63 (1993) 16-23.

[15] Goldman A.S., Hulten M.A., Meiotic analysis by FISH of a human male $46, \mathrm{XY}, \mathrm{t}(15 ; 20)(\mathrm{q} 11.2 ; \mathrm{q} 11.2)$ translocation heterozygote: quadrivalent configuration, orientation and first meiotic segregation, Chromosoma 102 (1993) $102-111$.

[16] Guttenbach M., Engel W., Schmid M., Analysis of structural and numerical chromosome abnormalities in sperm of normal men and carriers of constitutional chromosome aberrations. A review, Hum. Genet. 100 (1997) 1-21.

[17] Hassanane M., Kovacs A., Laurent P., Lindblad K., Gustavsson I., Simultaneous detection of X- and Y-bearing bull spermatozoa by double colour fluorescence in situ hybridization, Mol. Reprod. Dev. 53 (1999) 407-412.

[18] Hawken R.J., Murtaugh J., Flickinger G.H., Yerle M., Robic A., Milan D., Gellin J., Beattie C.W., Schook L.B., Alexander L.J., A first-generation porcine wholegenome radiation hybrid map, Mamm. Genome 10 (1999) 824-830.

[19] Honda H., Miharu N., Ohashi Y., Honda N., Tetsuaki H., Ohama K., Analysis of segregation and aneuploidy in two reciprocal translocation carriers, $\mathrm{t}(3 ; 9)(\mathrm{q} 26.2 ; \mathrm{q} 32)$ and $\mathrm{t}(3 ; 9)(\mathrm{p} 25 ; \mathrm{q} 32)$, by triple-color fluorescence in situ hybridization, Hum. Genet. 105 (1999) 428-436. 
[20] Honda H., Miharu N., Samura O., He H., Ohama K., Meiotic segregation analysis of a 14;21 Robertsonian translocation carrier by fluorescence in situ hybridization, Hum. Genet. 106 (2000) 188-193.

[21] Jaarola M., Martin R.H., Ashley T., Direct evidence for suppression of recombination within two pericentric inversions in humans: a new sperm-FISH technique, Am. J. Hum. Genet. 63 (1998) 218-224.

[22] Jalbert P., Sele B., Jalbert H., Reciprocal translocations: a way to predict the mode of imbalanced segregation by pachytene-diagram drawing, Hum. Genet. 55 (1980) 209-222.

[23] Kawarasaki T., Welch G.R., Long C.R., Yoshida M., Johnson L.A., Verification of flow cytometrically-sorted $\mathrm{X}$ - and Y-bearing porcine spermatozoa and reanalysis of spermatozoa for DNA content using the fluorescence in situ hybridization (FISH) technique, Theriogenology 50 (1998) 625-635.

[24] Oliver-Bonet M., Navarro J., Codina-Pascual M., Carrera M., Egozcue J., Benet J., Meiotic segregation analysis in a t $(4 ; 8)$ carrier: comparison of FISH methods on sperm chromosome metaphases and interphase sperm nuclei, Eur. J. Hum. Genet. 9 (2001) 395-403.

[25] Pellestor F., Girardet A., Coignet L., Andreo B., Lefort G., Charlieu J.P., Cytogenetic analysis of meiotic segregation in sperm from two males heterozygous for reciprocal translocations using PRINS and humster techniques, Cytogenet. Cell Genet. 78 (1997) 202-208.

[26] Pellestor F., Imbert I., Andréo B., Lefort G., Study of the occurrence of interchromosomal effect in spermatozoa of chromosomal rearrangement carriers by fluorescent in situ hybridization and primed in situ labelling techniques, Hum. Reprod. 16 (2001) 1155-1164.

[27] Pinton A., Ducos A., Berland H.M., Seguela A., Brun-Baronnat C., Darré A., Darré R., Schmitz A., Yerle M., Chromosomal abnormalities in hypoprolific boars, Hereditas 132 (2000) 55-62.

[28] Piumi F., Vaiman D., Cribiu E.P., Guérin B., Humblot P., Specific cytogenetic labeling of bovine spermatozoa bearing $\mathrm{X}$ or $\mathrm{Y}$ chromosomes using fluorescent in situ hybridization (FISH), Genet. Sel. Evol. 33 (2001) 89-98.

[29] Popescu C.P., Cytogénétique des mammifères d'élevages, INRA Éditions, Paris.

[30] Popescu C.P., Bonneau M., Tixier M., Bahri I., Boscher J., Reciprocal translocations in pigs. Their detection and consequences on animal performance and economic losses, J. Hered. 75 (1984) 448-452.

[31] Rens W., Yang F., Welch G., Revell S., O’Brien P.C., Solanky N., Johnson L.A., Ferguson-Smith M.A., An X-Y paint set and sperm FISH protocol that can be used for validation of cattle sperm separation procedures, Reproduction 121 (2001) 541-546.

[32] Rives N., Mazurier S., Bellet D., Joly G., Mace B., Assessment of autosome and gonosome disomy in human sperm nuclei by chromosome painting, Hum. Genet. 102 (1998) 616-623. 
[33] Rogel-Gaillard C., Bourgeaux N., Billault A., Vaiman M., Chardon P., Construction of a swine BAC library: application to the characterization and mapping of porcine type C endoviral elements, Cytogenet. Cell Genet. 85 (1999) 205-211.

[34] Rubes J., Vozdova M., Kubickova S., Aneuploidy in pig sperm: multicolor fluorescence in situ hybridization using probes for chromosomes 1, 10, and Y, Cytogenet. Cell Genet. 85 (1999) 200-204.

[35] Rudak E., Jacobs P.A., Yanagimachi R., Direct analysis of the chromosome constitution of human spermatozoa, Nature 274 (1978) 911-913.

[36] Schwerin M., Blottner S., Thomsen P.D., Roschlau D., Brockmann G., Quantification of Y chromosome bearing spermatozoa of cattle using in situ hybridization, Mol. Reprod. Dev. 30 (1991) 39-43.

[37] Tease C., Analysis using dual-colour fluorescence in situ hybridization of meiotic chromosome segregation in male mice heterozygous for a reciprocal translocation, Chromosome Res. 4 (1996) 61-68.

[38] Tease C., Chiasma distributions and chromosome segregation in male and female translocation heterozygous mice analysed using FISH, Chromosoma 107 (1998) 549-558.

[39] Tribout T., Ducos A., Maignel L., Bidanel J.P., Utilisation du système d'information BLUP pour la détection des verrats porteurs d'anomalies chromosomiques, Techniporc 23 (2000) 19-24.

[40] Van Hummelen P., Manchester D., Lowe X., Wyrobek A.J., Meiotic segregation, recombination, and gamete aneuploidy assessed in a $\mathrm{t}(1 ; 10)(\mathrm{p} 22.1 ; \mathrm{q} 22.3)$ reciprocal translocation carrier by three- and four-probe multicolor FISH in sperm, Am. J. Hum. Genet. 61 (1997) 651-659.

[41] Yerle M., Goureau A., Gellin J., Le Tissier P., Moran C., Rapid mapping of cosmid clones on pig chromosomes by fluorescence in situ hybridization, Mamm. Genome 5 (1994) 34-37.

To access this journal online: www.edpsciences.org 